Document downloaded from:

http://hdl.handle.net/10251/83244

This paper must be cited as:

Payri Marín, R.; Viera-Sotillo, JP.; Wang, H.; Malbec, L. (2016). Velocity field analysis of the high density, high pressure diesel spray. International Journal of Multiphase Flow. 80:69-78. doi:10.1016/j.ijmultiphaseflow.2015.10.012.

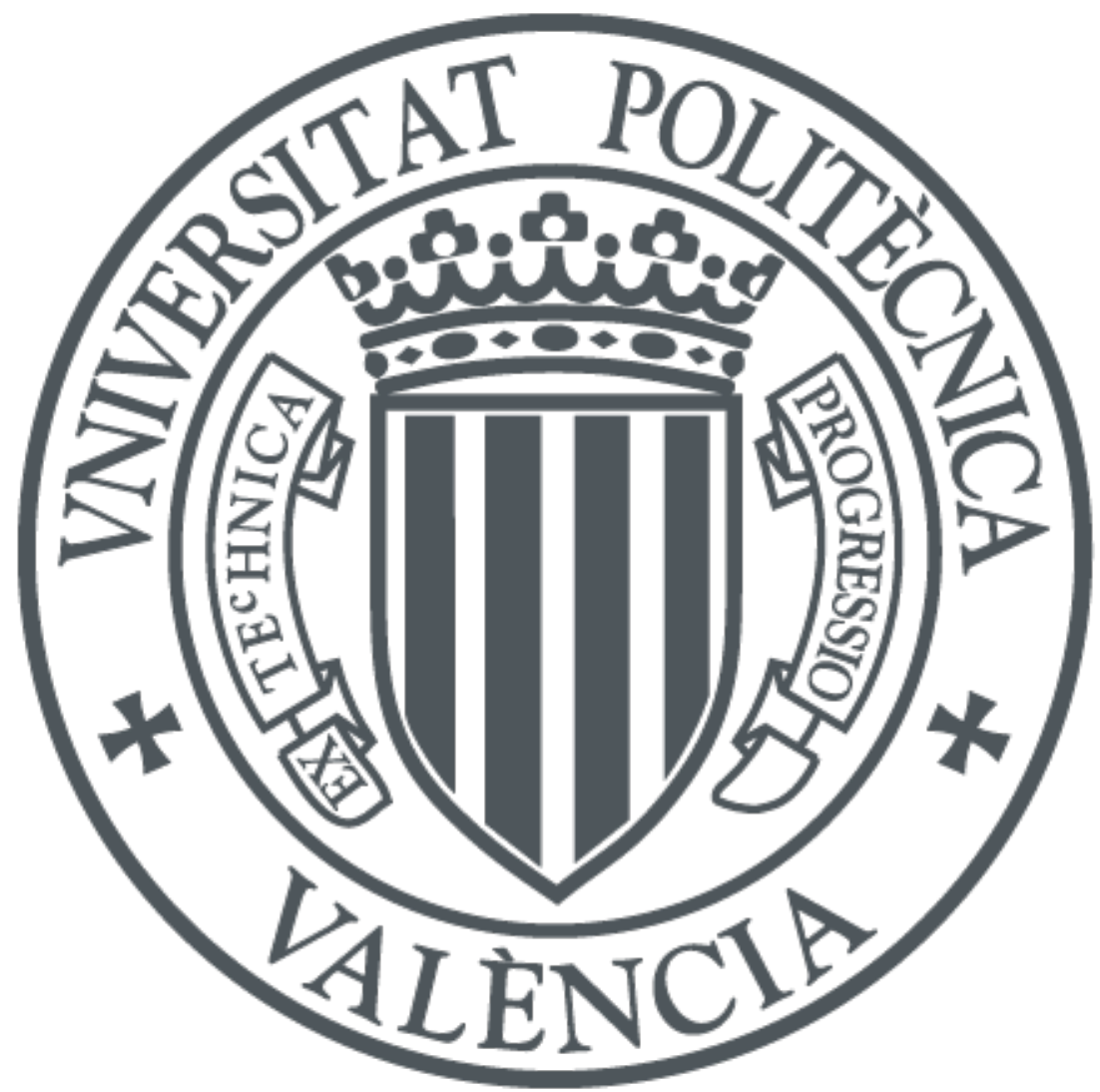

The final publication is available at

http://doi.org/10.1016/j.ijmultiphaseflow.2015.10.012

Copyright Elsevier

Additional Information 


\title{
Velocity field analysis of the high density, high pressure diesel spray
}

\author{
Raul Payri ${ }^{1}$, Juan P. Viera ${ }^{1}$, Hua Wang ${ }^{2,}$ Louis-Marie Malbec $^{3}$ \\ 1: CMT- Motores Térmicos - Universitat Politècnica de València, Camino de Vera s/n, 46022, Valencia - \\ SPAIN. \\ E-mail: $\quad$ rpayri@mot.upv.es \\ Phone: $\quad+(34) 963879658$ \\ Fax: $\quad$ +(34) 963877659
}

2: Department of Energy, Politecnico di Milano, Via Lambruschini 4, 20156, Milan - ITALY.

3: IFPEN, 1 \& 4, avenue de Bois-Préau, 92852 Rueil-Malmaison Cedex-FRANCE.

\begin{abstract}
In this study, particle image velocimetry (PIV) measurements have been performed extensively on a nonreactive dense diesel spray injected from a single orifice injector, under various injection pressure and steady ambient conditions, in a constant flow chamber. Details of PIV setup for diesel spray measurement without additional seeding are explained first. The measured velocity profiles are compared to those obtained from other similar measurements performed in a different institution, as well as those obtained from a 1D spray model simulation, presenting in both cases a good level of agreement. In addition, the velocity fields under various injection pressures and ambient densities show the dominant effects of these parameters on the behavior of diesel spray. The self-similarity of the transverse cut profiles of axial velocity is evaluated, showing that the measurements are in agreement with the hypothesis of self-similar velocity profiles. Finally, the effect of injection pressure and ambient density on the velocity fluctuations is presented and analyzed as well. While the experimental results presented here could help to understand the complex diesel fuel-air mixing process during injection, they also provide additional spray velocity data for future computational model validation, following the main idea of the Engine Combustion Network.
\end{abstract}

Keywords: diesel spray, PIV, velocity field

\section{Introduction}

The air-fuel mixing process is one of the key processes governing the combustion and the pollutant formation in diesel engines (Mobasheri et al., 2012; Pickett and Siebers, 2004). Solutions to recent and ever increasing concerns of fuel efficiency and pollutant emissions are, therefore, closely linked to a better understanding of this mixing process. Because of this, the diesel spray development has been extensively 
studied, and the characteristics of liquid phase (Bardi et al., 2012; Herfatmanesh et al., 2013; Naber and Siebers, 1996; Payri et al., 2012; Payri et al., 2013a) and vapor penetration (Bardi et al., 2012; Herfatmanesh et al., 2013; Pastor et al., 2012; Payri et al., 2013b) are now quite well known. These experiments have enabled the development of very useful 1D spray models (Desantes et al., 2009; Desantes et al., 2007; Musculus and Kattke, 2009; Pastor et al., 2008; Pickett et al., 2011)] that allow for fast and reliable predictions that effectively reduce testing times and costs necessary for new developments to comply with efficiency standards, emission regulations, etc.

However, relatively few studies have focused on velocity fields inside the spray, which are of great importance for model validation (Kolakaluri et al., 2010). Payri et al. (2008) have performed PDPA (phase doppler particle analyzer) on the spray recently; they found that the application of this technique to diesel sprays is challenging and has certain limitations imposed firstly by the high droplet number concentration and secondly by the droplets typical high velocity and small size. Particle Image Velocimetry (PIV) is another laser diagnostics technique which can be utilized to measure instantaneous velocity of complex flow fields. Many authors have employed this technique in fuel sprays with external seeding (Cao et al., 2000; Driscoll et al., 2003; Meijer et al., 2012a; Zhu et al., 2012a) but out of these studies, only Cao et al. (2000) and Meijer et al. (2012a) perform measurements of the velocity field inside the high ambient density diesel spray. Moreover, to the authors' knowledge, there are very few authors that have successfully measured spray internal velocity fields without the use of seeding particles (Zama et al., 2012; Zama et al., 2013; Zhu et al., 2012b). Out of all these PIV experiments, only Meijer et al. (2012a), Zama et al. (2012), Zama et al. (2013) and Zhu et al. (2012b) have performed internal spray velocity measurements for current-trend small nozzle (of outlet diameter Do $<200 \mu \mathrm{m}$ ), high injection pressure and high ambient density conditions.

The main goal of this paper is to analyze the velocity fields inside the non-vaporizing, high ambient density diesel spray, through planar seeding-free PIV analysis. This is relevant not only because non-vaporizing sprays present very similar behaviors to vaporizing sprays for mixing processes (Hiroyasu and Arai, 1990; Naber and Siebers, 1996; Payri et al., 2014; Zhu et al., 2012b), but also because performing PIV in vaporizing, high ambient density/injection pressure conditions presents a real challenge regarding the experimental test rig and the correct supply of seeding particles.

Therefore, velocity field measurements were carried out for different test conditions. To further evaluate the measurements, a well-documented nozzle and set of test conditions were selected. The evaluation of the measurements consists of comparing both similar experiments performed at two different institutions (CMTMotores Térmicos using liquid fuel droplets as tracers and IFP Energies Nouvelles using ceramic nanoparticle seeds) and also comparing experimental results with a well-documented 1D spray model, first introduced by Desantes et al. (2009; 2007), and Pastor et al. (2008). Finally, after the assessment of the seeding-free technique is presented, an analysis of the experimental velocity field at parametric variations of injection pressure and ambient density is held. 


\section{Experimental setup and methodology}

\subsection{The fuel injection system}

A common-rail injection system was employed during the experiments, which allows injection pressure up to 2000 bar (Payri et al., 2012; Payri et al., 2013a; Payri et al., 2013b). The fuel utilized was n-dodecane, injected through a single orifice nozzle (ECN nozzle 210675, BOSCH solenoid actuated injector) (Kastengren et al., 2012), with an outlet diameter $\mathrm{D}_{0}=89.4 \mu \mathrm{m}$ and a k-factor $=1.5$. The injector tip temperature was controlled using a customized injector holder, which guarantees the uniform temperature through the whole injector body. The nozzle is also isolated from the chamber temperature with a ceramic shield liner which features a small axial orifice to allow the free pass of the fuel spray.

\subsection{The high pressure and high temperature test rig}

The tests have been performed in a high temperature, high pressure, constant flow test chamber where the in-cylinder thermo-dynamic conditions of a diesel engine at the time of injection can be reproduced. The test chamber allows a maximum ambient temperature of $1000 \mathrm{~K}$ and maximum pressure of $150 \mathrm{bar}$. The test section has three large windows (128 mm in diameter) placed orthogonally in order to have complete optical access to the injection-atomization process. The complete test rig functioning and principles are precisely described in previous works presented by Payri et al. (2013a; 2013b; 2015). In this study, the vessel was filled with nitrogen to guarantee the non-reacting conditions sought.

Since the injector tip is directly exposed to the chamber gas, the actual injector tip temperature depends on the chamber gas temperature, chamber gas density, and injector coolant temperature (Payri et al., 2012). Thus, injector coolant temperature was adjusted according to the chamber conditions to guarantee the ECN injector tip temperature requirement of $363 \mathrm{~K}$.

\subsection{Experimental test matrix}

The experimental test matrix, presented in ¡Error! No se encuentra el origen de la referencia., focuses on studying the velocity field of a steady, fully developed spray at different test conditions. The injector utilized, the ambient densities and injection pressures selected are those of interest to the Engine Combustion Network (ECN) (Bardi et al., 2012; Kastengren et al., 2012; Meijer et al., 2012b). The ECN is a worldwide group of institutions that perform experiments and computational fluid dynamics, whose aim is to advance the state of spray and combustion knowledge at engine-relevant conditions. This initiative has permitted the construction of a large, public set of experimental data based on a particular point of working conditions: the so called "Spray A" condition is a low-temperature combustion condition relevant to engines that use moderate EGR. The main target of this experimental dataset is to enhance model validation capabilities and overall knowledge and understanding of the diesel sprays.

Published as: R. Payri et al. / International Journal of Multiphase Flow 80 (2016) 69-78 
In this case, the study seeks to enhance the ECN database by providing velocity fields and turbulent statistical behavior for the Spray A test conditions and parametric variations around these. Compared to the standard ECN Spray A conditions, a lower ambient temperature condition (500 K) was selected to achieve the adequate droplet density for PIV measurements - since the fuel droplets are the actual tracers for the velocity measurements. Higher ambient temperatures would cause evaporation of most of the fuel droplets and thus leave few droplets left to trace. Since ambient temperature was kept at $500 \mathrm{~K}$, ambient pressures were adjusted accordingly to obtain the target ambient densities inside the chamber (see ¡Error! No se encuentra el origen de la referencia.). Note that the dimensionless numbers presented in ¡Error! No se encuentra el origen de la referencia. are calculated at the orifice outlet, with the hydraulic performance data available for this nozzle from the ECN experimental campaigns (Kastengren et al., 2012).

¡Error! No se encuentra el origen de la referencia.

\begin{tabular}{llc}
\hline Target parameter & Values & Units \\
\hline Fuel & n-dodecane & - \\
Nozzle reference & 210675 & - \\
Outlet diameter & 89.4 & $\mu \mathrm{m}$ \\
Nominal k-factor & 1.5 & - \\
Ambient Temperature & 500 & $\mathrm{~K}$ \\
Ambient Density & $22.8-15.2-7.6$ & $\mathrm{~kg} / \mathrm{m}^{3}$ \\
Ambient pressure & $33.2-21.9-11.0$ & $\mathrm{bar}$ \\
Injection pressure & $500-1000-1500$ & $\mathrm{bar}$ \\
Reynolds number & $3.18 \mathrm{e} 4-4.58 \mathrm{e} 4-5.65 \mathrm{e} 4$ & - \\
Weber number & $3.23 \mathrm{e} 5-6.89 \mathrm{e} 5-10.32 \mathrm{e} 5$ & - \\
Ohnesorge number & $1.8 \mathrm{e}-3-1.8 \mathrm{e}-3-1.8 \mathrm{e}-3$ & - \\
Injector coolant temperature & 343 & $\mathrm{~K}$ \\
Oxygen concentration & 0 &
\end{tabular}

The flow field of the steady, fully developed liquid spray is the main concern of this study. Therefore, the laser timing with respect to the injector trigger signal (Start of Energizing, SOE) was set so that images were acquired late enough to guarantee a steady, fully developed spray, but the tip of the spray remained inside the frame so as to allow for velocity measurements in the spray tip region. This means that the actual frame timing with respect to the SOE is not constant through the test matrix, but adjusted to find the above criteria for each test condition. 


\subsection{Optical setup}

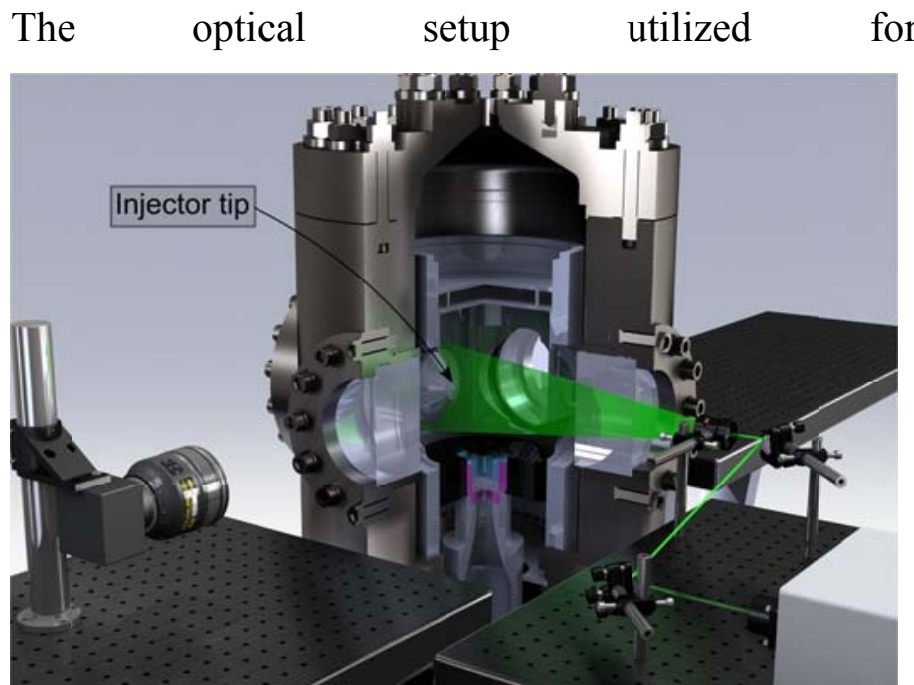

Fig. 1) consisted in a two-dimensional PIV setup, constituted by a double-pulse Nd:YAG laser, two laser mirrors, sheet optics and a double pulse camera. The camera, situated perpendicular to the laser sheet plane, captured light scattered by the liquid droplets in the spray. The laser was introduced from the front of the spray tip, towards the nozzle. Although frontal illumination produces an unbalanced intensity distribution along the macroscopic spray (a strong light attenuation was found near the injector tip), it has been proved to have a negligible effect on an analysis such as a PIV (Dankers et al., 2008), which was observed in this study as well. ¡Error! No se encuentra el origen de la referencia. summarizes the rest of the optical setup components and characteristics:

¡Error! No se encuentra el origen de la referencia.

\begin{tabular}{|c|c|}
\hline Acquisition camera & TSI PowerView ${ }^{\mathrm{TM}}$ Plus 4MP Camera \\
\hline Camera lens & Zeiss 100mm f/2.0 Makro-Planar \\
\hline Laser & Litron Nano L PIV \\
\hline Laser type & Double pulsed Nd:YAG \\
\hline Laser head power output @ 532 nm [mJ] & 135 \\
\hline Laser pulse duration $[\mathrm{ns}]$ & 6 \\
\hline Double pulse time step $[\mu \mathrm{s}]$ & $20-10-8$ \\
\hline Laser sheet thickness [mm] & $<0.5$ \\
\hline Mirrors & Edmund Optics Nd:YAG specific \\
\hline Image size [pixels] & $2048 \times 2048$ \\
\hline Image pixel $/ \mathrm{mm}$ ratio $[\mathrm{pixel} / \mathrm{mm}]$ & 21.63 \\
\hline Number of repetitions & 25 \\
\hline
\end{tabular}

The time step between frames is also another important variable in a proper setup PIV system. If set too short, the very small particle movements detected become comparable to pixel wise spatial resolution, and actual velocity measurements are then left to sub-pixel interpolations which can introduce additional problems in small particles, where peak locking may occur (Cholemari, 2007; Overmars et al., 2010). A certain amount of particle movement (thus, a long enough time step) is needed in order to reduce spatial resolution related issues. However, considering the very wide range of velocities in the field of measurement 
and the high turbulence/strong dimensional properties of the spray flow, time steps were adjusted to find the best compromise possible between these criteria.

In addition, spray particle velocities depend on various variables, with the most important being (for a given axial and radial location in the spray) the injection pressure and ambient density. Time steps were adjusted depending also on test conditions, to properly limit the maximum particle displacement to $30 \%$ of the interrogation window size.

\subsection{Image Processing}

Image pairs were processed with commercial software INSIGHT 3G. Before processing, image masking and background subtraction were applied sequentially.

The cross-correlation calculations employed a multi-pass algorithm, to increase accuracy and resolution of the results. Spot pixel resolutions were set to $128 \times 64$ for the first pass and $64 \times 32$ for the rest. The spots selected were not squared because it was expected for the axial component of the velocities to be much larger than the radial component (Desantes et al., 2009; Meijer et al., 2012a).

Prior to each of the cross-correlation calculations, every spot in the image is also corrected with a Gaussian weighting function so that the center of the spot is bright and the edges fade out. This strategy ensures that the center of the spot contributes more to the correlation map than the edges, which serves as a quality enhancer for the correlation maps since it reduces the impact that loses (or inclusions) of particles near the edges of the spots, caused by the different velocity directions involved, have over the correlation map. In practice, this increases the signal-to-noise ratio which consequently reduces the random pairing peak sizes and overall noise in the correlation maps.

\subsection{Post processing}

Each velocity field obtained went through a post processing sequence to enhance or guarantee its quality and physical meaning. Statistical outliers were detected and rejected by employing global and local standard deviation analyses. Holes left by these rejected vectors are filled with the local median.

Although a single-shot velocity field will be presented later, the paper will focus on the ensemble average velocity fields; because these better show the influence of various parameters on the spray development and they are very useful for model validation. 


\section{Results}

\subsection{Single injection velocity field}

As stated in the previous section, an individual velocity field was obtained for every single injection at a given set of tests conditions. Fig. 2 depicts an example of one of these velocity fields, where vectors have been plotted over the original scattered image.

Several important aspects of this figure have to be described before further analysis:

- The image shown is a cropped section of the actual image (original image resolution can be found in ¡Error! No se encuentra el origen de la referencia.). The rest of the image is black and does not add important information to this analysis so it was removed to focus on the important area.

- Yellow vectors are those validated by all validation checks, stored for analysis. Red vectors are statistical outliers that were rejected in the last check, and are shown as examples.

- There is a certain length, near the nozzle, where no velocity fields can be detected. This occurs because in this area the droplet concentration is too high, which results in poor signal-to-noise ratios that do not permit reliable velocity measurements. Also, the high droplet concentration may cause multiple scattering problems in this area, which introduce additional uncertainty to the PIV analysis.

- There are no measured vectors in areas where pre-processing image masking was performed, or the spots did not comply with the minimum average intensity requirements.

- It is imperative to clarify that, since this is just a figure to illustrate a particular result, the intensity scale in the image presented is logarithmic to better show the lower intensity areas. Nonetheless, it can be observed that scattered intensity throughout the image is not constant which is, of course, expected. For this reason, light intensity has to be controlled to obtain the proper dynamic range in the images. Here, it is again important to remark that the image shown is raw from the camera and is very different from the actual image that is correlated, which has gone through all of the preprocessing steps that help enhance the signal-to-noise ratio of the correlation maps. Note also that the logarithmic intensity scale will reduce the "apparent" signal-to-noise ratio, in the image shown.

- The velocity field presented shows turbulent flow, which is expected. The top and bottom part of the spray tip feature the typical two big vortices expected to exist in that zone, which are caused by the aerodynamic balance between the spray tip penetration and the radial air entrainment. The spray contour shows the branch-type morphologies and the velocities within the spray present a "pulsing" behavior (shown in the image as velocities vectors of different magnitude) typical of turbulent flows.

\subsection{Ensemble average velocity field}

The ensemble average calculation cancels out many of these turbulence-associated behaviors and renders an average velocity field that is considerably smoother than the single-shot velocity field.

Fig. 3 depicts this velocity field for a given test condition, as an example. It is necessary to clarify that, as explained in section 3.1, it was not possible to measure velocities in the near-nozzle region. Therefore, the velocity fields and profiles Published as: R. Payri et al. / International Journal of Multiphase Flow 80 (2016) 69-78 
presented in this paper are not a complete representation of the spray. Note that, moving across the spray towards the tip, the cutoff point where the measurements are not possible or valid depends on test conditions and spray characteristics; for the particular case of

Fig. 3, the velocity fields where discarded below $36 \mathrm{~mm}$ from the nozzle, since measurements from this point down were considered the result of random pairing because of the poor signal-to-noise ratio acquired in that zone.

\section{It can be seen in}

Fig. 3 that the ensemble averaged field does not show the strong turbulent behavior typical of an injection spray at this conditions, although it holds the radial spreading tendency of the spray. Near the tip, there seems to be a tendency for the spray to spread even more, suggesting that the two vortices that typically form at both side of the tip appear consistently in most of the 25 fields obtained. Another important observation is that the peak velocity is lower for the ensemble average than the peak velocity likely to be found in any of the single shot velocity fields. Either way, these ensemble average fields still hold very useful information that can be extracted to analyze the velocity response of the spray to different injection conditions and that can be utilized for model validation. From this point on, all velocity fields and profiles presented are obtained from the ensemble averages.

\subsection{Validation of measurements against experimental data}

A comparable PIV study was carried out by Meijer et al. (2012a). In the study, the authors perform timeresolved measurements of the spray velocities in both inert and reacting Spray A conditions. A very similar injector was employed (210678 nozzle for the ECN, see Kastengren et al. (2012)) in a constant volume vessel and results of the ensemble average of 20 injections are presented. In particular, the authors present transverse cut profiles of axial velocity but regarding only Spray A conditions. Note that additional measurements from the same test campaign that produced the results previously presented by Meijer et al. (2012a) are presented in this paper.

Fig. 4 shows the first evaluation of measurements performed in this study, comparing against the reference Spray A conditions already presented by Meijer et al. (2012a), and two additional test conditions of ambient density and injection pressure respectively.

The figure addresses two separate validations: first, a comparison of the results obtained in this study (labeled as CMT in the legend) to those of Meijer et al. (2012a)(labeled as IFPEN in the legend), and second an evaluation of an additional ambient density (Fig. 4a) and injection pressure variations (Fig. 4b).

As can be observed in Fig. 4, all velocity profiles show a Gaussian distribution as has been seen previously (Desantes et al., 2007; Meijer et al., 2012a; Pastor et al., 2008; Payri et al., 2008; Zama et al., 2012; Zama et al., 2013). A good agreement was found between the measurements from the two different institutions, as Fig. 4 illustrates. In average, the difference between the two sets of measurements was $8 \%$. This is a very important result, since it suggests that the simple PIV setup utilized for this study is valid, while set up properly, for non-reacting liquid spray studies. On the same lines, it is an important result regarding spray

Published as: R. Payri et al. / International Journal of Multiphase Flow 80 (2016) 69-78 
behavior because, once again, it confirms that the density is the key factor in spray development, since the ambient temperature for the two tests is considerably different and the densities are purposely matched. The major drawback of the technique utilized in this study is that it is limited only to liquid sprays, but on the other hand it is as simple and non-intrusive as it can get. Seeding particles to a high pressure chamber can be a considerable challenge. Also, a low temperature test rig is much common and easier to get access to than a high temperature test rig, so experiments demand considerably less time and cost. It is crucial to stress that the boundary conditions were, in both cases, carefully controlled (Bardi et al., 2012; Meijer et al., 2012b), but the IFPEN-labeled measurements were done at an ambient temperature of $900 \mathrm{~K}$ with ceramic nanoparticle seeding, so the techniques and PIV setups are quite different, while still showing similar results for this particular case.

Moreover, although similar tendencies are found in both cases, CMT velocities seem slightly higher and the profiles slightly wider. It is important to point out that the small difference is well under the experimental dispersion for both experiments. However, it is expected for the non-vaporizing spray to show slightly higher velocities and wider profiles since, in high temperatures, the fuel/air mixture within the spray gets denser as the entrained hot gases are cooled by the evaporating fuel, and more important, momentum exchange is enhanced when the spray is in vapor state. These processes contribute to slowing down the spray, as has been seen in spray tip penetration measurements (Hiroyasu and Arai, 1990; Naber and Siebers, 1996; Payri et al., 2014; Zhu et al., 2012b) and confirmed in internal velocity measurements presented by Zhu et al. (2012b). However, the real magnitude of this effect, regarding internal velocity profiles, is still to be determined. Zhu et al. (2012b) only compare time-dependent sample frames and neither the present study or the work of Meijer et al. (2012a) have the experimental resolution needed for such conclusion.

\subsection{Laser timing}

The timing criteria, as explained in section 2.3, consisted in acquiring the images at a certain time with respect to SOE early enough so that the tip of the spray still remained inside the frame, thus allowing measurements in this area, but at the same time, acquiring the images as late as possible so to guarantee a fully developed spray upstream of the spray tip. In order to assess if the timings utilized complied with this latter requirement, two separate tests were carried out at different timings: an early time that followed the criteria just explained (this was the timing criteria utilized throughout the whole test matrix) and a very late timing, where the tip of the spray had long exited the frame but the spray was, for sure, fully developed. Fig. 5 addresses this verification showing transverse cut profiles of axial velocity at two axial locations of $45 \mathrm{~mm}$ and $65 \mathrm{~mm}$ from the nozzle tip. As depicted in the figure, the early timing guarantees that the velocities measured in the developed region of the spray are similar to those of a fully developed spray, but still permit the velocity measurements near the tip of the spray, as Fig. 2 and 3 show.

Fig. 6 also shows the two timing cases studied, but in this case for longitudinal axial velocity profiles. This confirms once again that the early timing criteria complies with the fully developed spray requirements. It is 
important to mark that the velocities measured in the proximity of image boundary are not to be considered valid, and for this reason, velocities in this area (towards the $90 \mathrm{~mm}$ mark) are not presented for the later timing case (4500 $\mu \mathrm{s}$ after SOE). On the other hand, it can be seen that the earlier timing case (3300 $\mu$ s after SOE) presents a subtle decrease in velocities near the spray tip. These velocities are considered valid and show the expected behavior when previous results are accounted for (Meijer et al., 2012a; Pastor et al., 2008). This slope near the tip is additional evidence to the momentum exchange between the spray and the ambient gas and the decrease in axial velocity characteristic of the vortices at the spray tip region. Overall, the difference between the two tests at different timings was $7 \%$ in average, note that this is calculated excluding the spray tip where the velocities decrease for the early timing case.

\subsection{Comparison to 1D spray model}

A 1D spray model (Desantes et al., 2009; Desantes et al., 2007; Pastor et al., 2008) was set up to the experimental test conditions and simulations were run to compare results with the PIV measurements. In the model, transverse velocity profiles are constructed as Gaussian distributions around a centerline or axis velocity, which is one of the results of the actual 1D simulation. Thus, a comparison of longitudinal velocity profiles at the centerline of the spray is depicted in Fig. 6. Note that, in the case of experimental measurements, the "centerline" is constructed by locating the spray tip vertical position in the image.

Fig. 6 illustrates good agreement found between the experimental measurements and the 1D model, which has been extensively utilized in both research and industry (Desantes et al., 2009; Desantes et al., 2007; Pastor et al., 2008). It is important to point out that the spray spreading angle is an input to the model and, since it is a largely uncertain parameter, in this type of models it is usually set so that the predicted spray tip penetration matches the experimental measurements for a given set of conditions (Desantes et al., 2009; Pastor et al., 2008; Pastor et al., 2012). Here lies one of the clear advantages of using a well characterized nozzle, since time-resolved spray tip penetration data, injection rates, etc. are openly available to calibrate the model. Further details on the development of this model and its hypotheses can be found in the work of Desantes et al. (2009) and Pastor et al. (2008).

It is important to point out here that the model does not solve the tip of the spray properly (Pastor et al., 2008). This is due to the fact that purely convective conservation equations are used, where radial diffusion is only accounted assuming self-similar radial profiles of velocities and fuel mass fraction. Thus, there is a steep drop in both centerline velocity and fuel mas fraction at the spray tip, which marks the maximum penetration. For this reason, velocities near the spray tip cannot be compared to the 1D model, and the velocity curve shown in Fig. 6 for the model represents a completely developed spray in which the spray tip is considerably far from the region windowed in the figure, representing then, the velocity profile of a steady, fully developed spray. 


\subsection{Effect of ambient density}

Several authors have studied the effect of ambient density on spray development (Desantes et al., 2009; Desantes et al., 2006; Hiroyasu and Arai, 1990; Naber and Siebers, 1996; Payri et al., 2011). All of these authors have found that ambient density is one of the key parameters in the spray development. Therefore, the ambient density was selected as the priority parameter to match those of Spray A condition, instead of temperature, which was not set to Spray A specifications (as explained in section 2.3).

Fig. 7 and 8 illustrate the effect of ambient density, both of which show that increasing density reduces the magnitude of the axial velocity profile. This result was repeated throughout the test matrix although only the most relevant test condition is shown. These tendencies were expected, since in many studies it can be seen that ambient density slows down spray tip penetration (Desantes et al., 2009; Desantes et al., 2006; Hiroyasu and Arai, 1990; Naber and Siebers, 1996; Payri et al., 2011), which is directly related to the in-spray velocity fields. Those studies also show, in terms of spray tip penetration, that the effect is not linear and attenuates as ambient density increases. A similar non-linearity can be observed in Fig. 7 and 8 in terms of axial velocity profiles, reported by Zama et al. (2012) as well. Moreover, Fig. 7 and 8 also show different deceleration slopes for the three densities; this is caused by the momentum exchange between the fuel and the air entrained, which increases with ambient density. The axial velocity dramatically decreases as the spray exits the nozzle, and downstream (where it is possible to measure velocities) the higher ambient density spray has lost considerably more momentum early in the chamber and thus the complete velocity profile is flatter. In the transverse profiles shown in Fig. 8 the slopes are results of the longitudinal velocity profile: a lower density presents higher velocities in the center (at a given axial distance) and thus higher shear-rates (slopes in the transverse profiles). The same tendencies can be observed for transverse and longitudinal axial velocity profiles reported by Payri et al. (2008) and for transverse axial velocity profiles presented by Zama et al. (2012).

\subsection{Effect of the injection pressure}

As with ambient density, several authors have exposed the effects of the injection pressure on spray development (Desantes et al., 2006; Hiroyasu and Arai, 1990; Naber and Siebers, 1996; Payri et al., 2013a; Payri et al., 2011). In these studies, authors found that the injection pressure increases the spray tip penetration rate. Thus, in this study the injection pressure 
is expected to increase droplet velocities in the spray. This effect is also present in the velocity profiles, as illustrated in

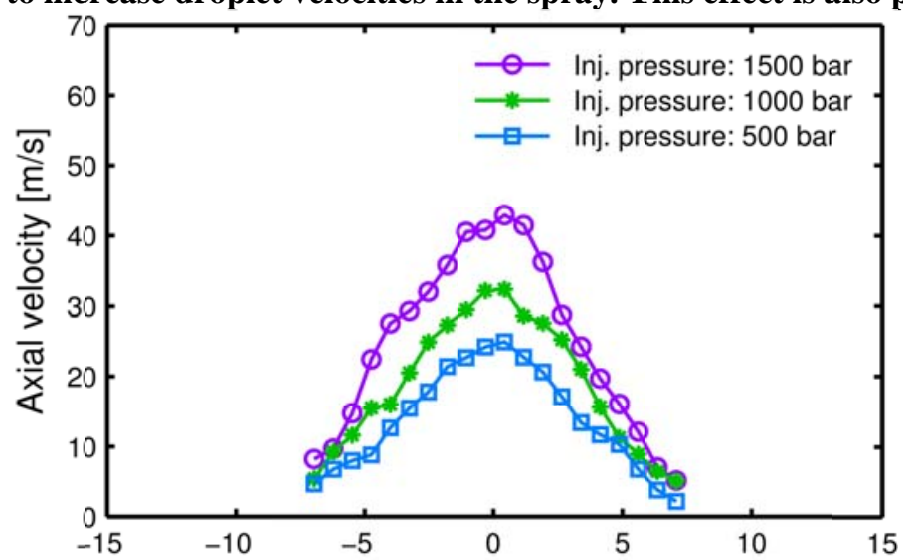

Fig. 9 and

Radial distance from axis [mm]

Fig. 10. It is important to note that the injection pressure increases not only the axial velocities at the centerline but also when moving along the radial direction.

Another important observation is that the effect of the injection pressure seems indeed linear, especially when comparing to the effect of the ambient density which showed a non-linear tendency.

\subsection{Self-similarity analysis}

Steady state sprays and gas jets are expected to feature self-similar velocity and mixture fraction profiles in the radial direction (Baskaya et al., 1997; Desantes et al., 2009; Desantes et al., 2007; Muñiz and Mungal, 2001; Pastor et al., 2008; Payri et al., 2008). This implies that each profile follows a particular fundamental profile shape, regardless of the injection conditions (i.e. injection pressure, ambient density) and axial location where the profile is being analyzed, that is then scaled to dimensions with the appropriate scaling parameters. To evaluate the self-similarity of the transverse-cut velocity profiles presented in this study, each profile was normalized by the corresponding centerline velocity at the axial distance at where the profile is taken. This is done for all test conditions, and the two axial locations presented in section 3.4 (45 $\mathrm{mm}$ and $65 \mathrm{~mm}$ ). Therefore, this renders the scatter plot presented in Fig. 11, where $U(x, r)$ is the axial velocity at a given axial location $x$ and radial location $r$, and $U_{C l}$ is the axial velocity in the centerline of the spray.

This result supports what Payri et al. (2008) found for comparable liquid diesel sprays, but in this case a much wider test matrix is considered in the normalized analysis. For reference, the theoretical self-similar Gaussian profile was fitted to the data (black dashed line in Fig. 11), with a resulting root mean square error of 0.07 . Note that the fundamental profile shape is, therefore, independent of the injection conditions or axial location, and it is then scaled with the centerline velocity and the spray size (or axial location, in this case) to produce a particular transverse cut profile. 


\subsection{Effect of the injection pressure and ambient density on velocity fluctuations}

The standard deviation obtained for each ensemble velocity field is a combination of factors that come from various sources. The main contribution to the standard deviations obtained is the turbulent behavior of the spray: causing that it is virtually impossible to capture two injections with similar instant velocity profiles. In other words, given a single axial and radial location inside the spray and time with respect to SOE, the resulting velocity vector may feature very different magnitudes and directions from one injection to the other. This behavior will be referred to as turbulent dispersion (Duret et al., 2012; Zhu et al., 2012b). This concept is different to what is considered shot-to-shot dispersion of an injector, which is also present in any study of this type. The latter refers to the injector, having a natural dispersion between different injections, not always producing the same injection event (in terms of injection rate and spray momentum), which can be reflected in macro variables like spray tip vapor or liquid penetration (Desantes et al., 2006; Payri et al., 2013a; Payri et al., 2013b). The turbulent dispersion, on the other hand, is not as macro as the shot-to-shot dispersion, and is the result of the high level of turbulence present in the spray, producing significant unpredictable local velocity fluctuations within the spray in space and time (Duret et al., 2012).

Furthermore, if the rest of the variables are controlled and maintained during a test at particular conditions, it is considered valid to assume that the standard deviation map obtained from the ensemble average is an approximate estimation of the physical velocity fluctuations found, between all test repetitions, for those particular test conditions.

Fig. 12 depicts the effect of injection pressure and ambient density on the standard deviation obtained from the ensemble average, for both axial and radial velocities. Each standard deviation presented is, at the same time, the mean of the standard deviation profile that the ensemble average renders at $45 \mathrm{~mm}$ from the injector tip. This was done to synthetize data into a presentable figure, where the effects of parametric variations are addressed.

As it can be observed in Fig. 12, increasing the injection pressure considerably increases the standard deviation of both axial and radial velocities which comes from increasing, not just the magnitude of the velocities involved (as shown in section 3.6), but also velocity fluctuations within the spray. Contrasting that, Fig. 12 also shows that, for the axial velocity fluctuations, increasing ambient density has the contrary effect, reducing not only the magnitude of the velocities (as shown in section 3.5), but also the velocity fluctuations. It is important to note that the effect of the densities is smaller than the effect of the pressure. A triplication in injection pressure produces, in average, a duplication in standard deviation of the axial velocities, while a decrease in density to a third of the largest value produces, in average, an increase in standard deviation of only a half of the value for the largest density. Note also that the response of the fluctuations of radial velocities to the parametric variations is different. In general, radial velocity fluctuations increase both with injection pressure and ambient density, which suggests that turbulence and mixing are enhanced. Finally, the fact that the effect of the injection pressure increases with ambient density must be pointed out, which is thought to occur due to the considerable increase in mixing rates.

Published as: R. Payri et al. / International Journal of Multiphase Flow 80 (2016) 69-78 
However, standard deviations can be misleading since they are related to a mean dimensional value. Each of the std. point presented in Fig. 12 can be normalized by calculating the ratio of that std. to the axial RMS velocity of the corresponding velocity profile at this axial location. This will be referred to as normalized axial velocity fluctuations as shown in Fig. 13. Note that this normalization now accounts for the overall effect that each variable (injection pressure and ambient density) has on the mean value, so the result is independent in this regard (similar to the self-similarity normalization presented in section 3.8), and can be considered an indicator of flow fluctuations in relative terms.

It is important to note in Fig. 13 that the normalized axial velocity fluctuation increases with both ambient density and injection pressure. This is an important conclusion as it is different from what looking only at Fig. 12 may suggest. Note also that the effects of injection pressure are amplified as density increases, in both the axial and radial velocity fluctuations. These trends suggest that increasing injection pressure and ambient density enhances mixing in terms of relative velocity fluctuations, which are caused by turbulence. This was also observed by Zhu et al. (2012b) in terms of vortex distributions and should be further analyzed with detailed numerical models or microscopic, localized, PIV analyses.

\section{Summary and conclusions}

This work sought to provide velocity field measurements for a single-hole diesel like injector employing a different PIV technique, in which the liquid droplets of fuels are used as tracers instead of seeding particles. It must be pointed out that the proper setup of the PIV system and processing algorithm is crucial for obtaining good measurements, as is the correct set up of the processing strategies.

The seeding-free PIV measurements were validated by comparing experimental results from two different institutions employing two different PIV setups. In addition, a comparison of experimental results against predictions of a well-known 1D model was also presented. From this validation analyses, the following conclusions can be drawn:

- Measurements of transverse-cut axial velocity profiles were compared to previous comparable work presented by Meijer et al. (2012a) at IFPEN with seeding particles. The comparison also presents new data of the same IFPEN experimental campaign that was not published at the time by Meijer et al. (2012a). The measurements presented in this work correlate well to the reference study, in which a similar injector was utilized at ECN Spray A evaporative conditions. A slight overestimation of velocities was found in the present measurements which are considered to be associated with the difference in ambient temperature and spray thermodynamic state. Overall, an average difference of $8 \%$ was observed, which is mostly found in the peaks and borders of the profiles.

- The agreement between the experimental measurements and predictions obtained from the 1D model, which was set up to match the spray tip penetration for the particular test conditions, was $7 \%$. 
This difference is mostly due to the fluctuations featured by the axial ensemble average velocity profiles, and should be reduced if the number of samples is increased.

This is a very important result, since it suggests that the simple PIV setup utilized for this study is valid for non-reacting diesel spray studies, while set up properly. Moreover, it is a non-intrusive method. The limitations of this technique are the impossibility to have information on the reactive sprays, velocities outside the spray and, especially, in the near field. After performing these experiments, the authors would recommend considerably increasing the number of samples acquired for each test conditions, which at the same time, can be very time-consuming and costly.

A parametric study was carried out to evaluate the influence of ambient density and injection pressure on the velocity fields and finally, on velocity fluctuations. An important group of conclusions may be extracted from the present study:

- Ensemble average velocity fields were obtained from 25 different injections. These averages confirm that the ambient density is the determining factor in the spray development and that the effect of ambient density is not linear. The velocity fields obtained for single injections show a turbulent flow, as expected. The spray contour shows the branch-type morphologies and the velocities within the spray present a "pulsing" behavior characteristic of turbulent flows. The effect of ambient density over the ensemble average velocity fields was found to be non-linear while the effect of injection pressure was found to be linear. Because of the strong turbulent behavior, the authors would recommend more than 25 repetitions for experiments with such a high degree of variability such as these.

- The self-similarity of the transverse-cut velocity profiles was evidenced, where a good fit of the theoretical Gaussian profile was found. This confirms that the fundamental shape of the velocity profiles is independent of the injection conditions.

- The evaluation of the velocity fluctuations for several injection pressures and ambient densities showed that 1) axial velocity fluctuations increase both with injection pressure and ambient density, when considering the behavior relative to the magnitude of the velocities involved and 2) the effects of injection pressure seem to be greater than those of the ambient density. This evidences, again, that increasing both the injection pressure and ambient density significantly increases the mixing rates.

In conclusion, this work provides a study of the velocity field within the diesel spray injection from a single orifice injector with planar, seeding-free PIV measurements that trace the actual droplet velocities. Finally, as previously stated, these results could be of good value for computational model validation and further discussion of the physics involved in such a complex process.

\section{Acknowledgements}


This work was sponsored by "Ministerio de Economía y Competitividad" of the Spanish Government in the frame of the Project "Comprensión de la influencia de combustibles no convencionales en el proceso de injección y combustión tipo diesel", Reference TRA2012-36932. Additionally, the optical equipment used for the project was purchased with funding from Ministerio de economia y competitividad FEDER-ICTS2012-06.

The authors would like to thank Michele Bardi and Jose Enrique Del Rey for their help and support during the experimental setup and tests.

\section{References}

Bardi, M., Payri, R., Malbec, L.M., Bruneaux, G., Pickett, L.M., Manin, J., Bazyn, T., Genzale, C.L., 2012. Engine combustion network: Comparison of spray development, vaporization, and combustion in different combustion vessels. Atomization and Sprays 22, 807-842.

Baskaya, S., Gilchrist, A., Fraser, S.M., 1997. The radial spread and axial decay of temperature in turbulent condensing jets. International Communications in Heat and Mass Transfer 24, 465-474.

Cao, Z.M., Nishino, K., Mizuno, S., Torii, K., 2000. PIV measurement of internal structure of diesel fuel spray. Experiments in Fluids 29, S211-S219.

Cholemari, M., 2007. Modeling and correction of peak-locking in digital PIV. Experiments in Fluids 42, 913-922.

Dankers, S., Gotthardt, M., Stengler, T., Ohmstede, G., Hentschel, W., 2008. Two-Phase PIV: Fuel-Spray Interaction with Surrounding Air, Particle Image Velocimetry. Springer Berlin Heidelberg, pp. 333-343.

Desantes, J.M., Pastor, J.V., García-Oliver, J.M., Pastor, J.M., 2009. A 1D model for the description of mixing-controlled reacting diesel sprays. Combustion and Flame 156, 234-249.

Desantes, J.M., Payri, R., Garcia, J.M., Salvador, F.J., 2007. A contribution to the understanding of isothermal diesel spray dynamics. Fuel 86, 1093-1101.

Desantes, J.M., Payri, R., Salvador, F.J., Gil, A., 2006. Development and validation of a theoretical model for diesel spray penetration. Fuel 85, 910-917.

Driscoll, K.D., Sick, V., Gray, C., 2003. Simultaneous air/fuel-phase PIV measurements in a dense fuel spray. Experiments in Fluids 35, 112-115.

Duret, B., Luret, G., Reveillon, J., Menard, T., Berlemont, A., Demoulin, F.X., 2012. DNS analysis of turbulent mixing in two-phase flows. International Journal of Multiphase Flow 40, 93-105.

Herfatmanesh, M.R., Attar, M.A., Zhao, H., 2013. Simultaneous imaging of diesel spray atomisation and evaporation processes in a single-cylinder CR diesel engine. Experimental Thermal and Fluid Science 50, $10-20$.

Hiroyasu, H., Arai, M., 1990. Structures of fuel sprays in diesel engines. SAE Technical Paper 900475.

Kastengren, A.L., Tilocco, F.Z., Powell, C.F., Manin, J., Pickett, L.M., Payri, R., Bazyn, T., 2012. Engine Combustion Network (ECN): Measurements of nozzle geometry and hydraulic behavior. Atomization and Sprays 22, 1011-1052.

Kolakaluri, R., Li, Y., Kong, S.-C., 2010. A unified spray model for engine spray simulation using dynamic mesh refinement. International Journal of Multiphase Flow 36, 858-869.

Meijer, M., Malbec, L.M., Bruneaux, G., Somers, L., 2012a. Engine Combustion Network: "Spray A" basic measurements and advanced diagnostics, ICLASS 2012, Heidelberg, Germany.

Meijer, M., Somers, B., Johnson, J., Naber, J., Lee, S.-Y., Malbec, L.M., Bruneaux, G., Pickett, L.M., Bardi, M., Payri, R., Bazyn, T., 2012b. Engine Combustion Network (ECN): Characterization and comparison of boundary conditions for different combustion vessels. Atomization and Sprays 22, 777-806.

Mobasheri, R., Peng, Z., Mirsalim, S.M., 2012. Analysis the effect of advanced injection strategies on engine performance and pollutant emissions in a heavy duty DI-diesel engine by CFD modeling. International Journal of Heat and Fluid Flow 33, 59-69.

Published as: R. Payri et al. / International Journal of Multiphase Flow 80 (2016) 69-78 
Muñiz, L., Mungal, M.G., 2001. Effects of heat release and buoyancy on flow structure and entrainment in turbulent nonpremixed flames. Combustion and Flame 126, 1402-1420.

Musculus, M.P.B., Kattke, K., 2009. Entrainment waves in diesel jets. SAE Technical Paper 2009-01-1355.

Naber, J., Siebers, D.L., 1996. Effects of Gas Density and Vaporization on Penetration and Dispersion of Diesel Sprays. SAE Technical Paper 960034.

Overmars, E., Warncke, N., Poelma, C., Westerweel, J., 2010. Bias error in PIV: the pixel locking effect revisited, $15^{\text {th }}$ Int. Symp. on Applications of Laser Techniques to Fluid Mechanics, Lisbon, Portugal.

Pastor, J.V., Javier López, J., García, J.M., Pastor, J.M., 2008. A 1D model for the description of mixingcontrolled inert diesel sprays. Fuel 87, 2871-2885.

Pastor, J.V., Payri, R., García-Oliver, J.M., Nerva, J., 2012. Schlieren Measurements of the ECN-Spray A Penetration under Inert and Reacting Conditions. SAE Technical Paper 2012-01-0456.

Payri, F., Payri, R., Bardi, M., Carreres, M., 2014. Engine Combustion Network: Influence of the gas properties on the spray penetration and spreading angle. Experimental Thermal and Fluid Science 53, 236-243.

Payri, R., García-Oliver, J.M., Bardi, M., Manin, J., 2012. Fuel temperature influence on diesel sprays in inert and reacting conditions. Applied Thermal Engineering 35, 185-195.

Payri, R., Gimeno, J., Bardi, M., Plazas, A.H., 2013a. Study liquid length penetration results obtained with a direct acting piezo electric injector. Applied Energy 106, 152-162.

Payri, R., Gimeno, J., Viera, J.P., Plazas, A.H., 2013b. Needle lift profile influence on the vapor phase penetration for a prototype diesel direct acting piezoelectric injector. Fuel 113, 257-265.

Payri, R., Salvador, F.J., Gimeno, J., Novella, R., 2011. Flow regime effects on non-cavitating injection nozzles over spray behavior. International Journal of Heat and Fluid Flow 32, 273-284.

Payri, R., Tormos, B., Salvador, F.J., Araneo, L., 2008. Spray droplet velocity characterization for convergent nozzles with three different diameters. Fuel 87, 3176-3182.

Payri, R., Viera, J.P., Pei, Y., Som, S., 2015. Experimental and numerical study of lift-off length and ignition delay of a two-component diesel surrogate. Fuel 158, 957-967.

Pickett, L.M., Manin, J., Genzale, C.L., Siebers, D., Musculus, M.P.B., Idicheria, C.A., 2011. Relationship between diesel fuel spray vapor penetration/dispersion and local fuel mixture fraction. SAE Int. J. Engines 4, 764-799.

Pickett, L.M., Siebers, D.L., 2004. Soot in diesel fuel jets: effects of ambient temperature, ambient density, and injection pressure. Combustion and Flame 138, 114-135.

Zama, Y., Ochiai, W., Furuhata, T., Arai, M., 2012. Velocity measurement inside a diesel spray by using time-resolved PIV under high ambient density condition, ICLASS 2012, Heidelberg, Germany.

Zama, Y., Ochiai, W., Sugawara, K., Furuhata, T., Arai, M., 2013. Study on mixing process of diesel spray under high ambient gas density condition. Atomization and Sprays 23, 443-461.

Zhu, J., Kuti, O.A., Nishida, K., 2012a. An Investigation of the Effects of Fuel Injection Pressure, Ambient Gas Density and Nozzle Hole Diameter on Surrounding Gas Flow of a Single Diesel Spray by laerinduced fluorescence--particle image velocimetry Technique. International Journal of Engine Research.

Zhu, J., Nishida, K., Kuti, O.A., 2012b. PIV study on flow fields of spray and surrounding gas under nonevaporating and evaporating conditions, ICLASS 2012, Heidelberg, Germany.

\section{Figure}




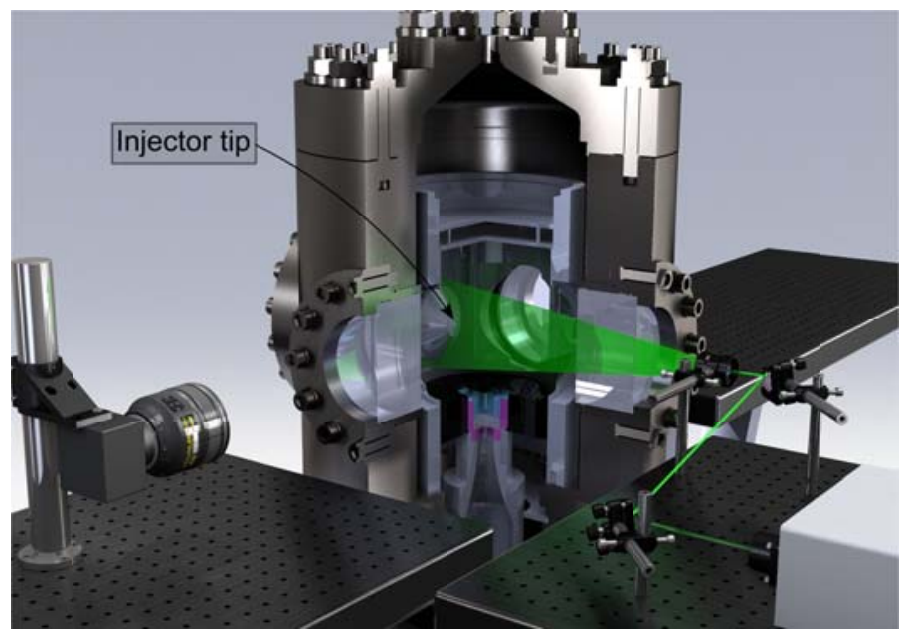

Fig. 1 Scheme of the optical setup utilized.

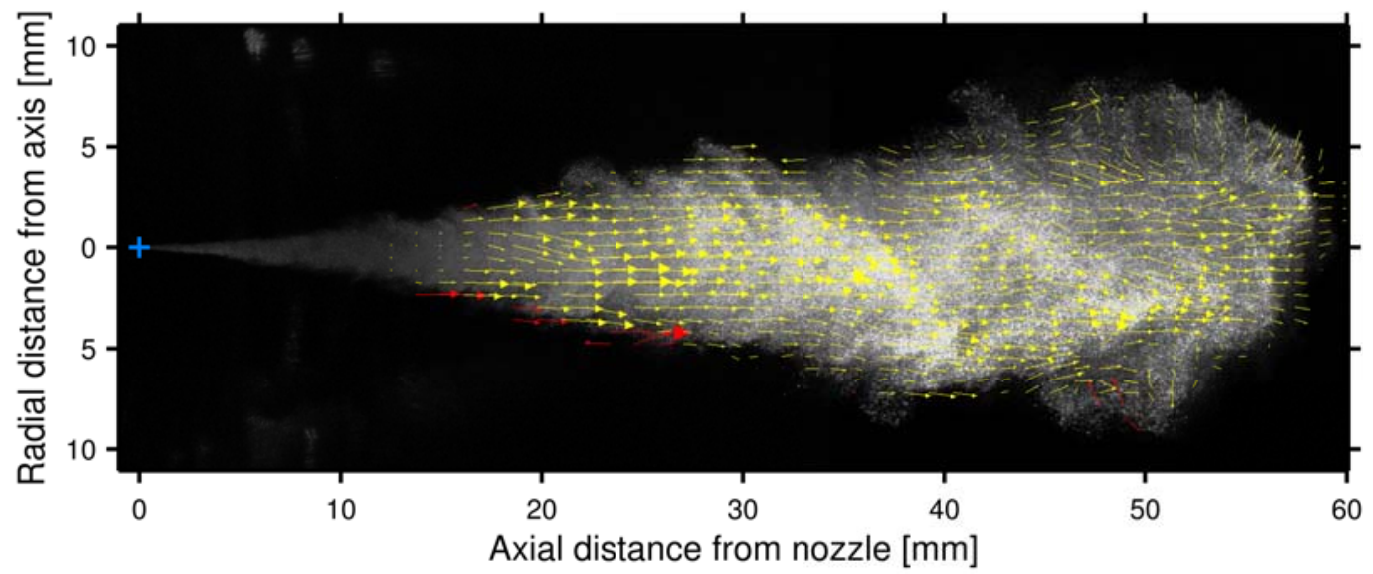

Fig. 2 Instantaneous velocity field obtained for a single injection in particular tests conditions. $P$ Pinj $=$ $500 \mathrm{bar}, \rho_{a}=22.8 \mathrm{~kg} / \mathrm{m}^{3}, \mathrm{Tamb}=500 \mathrm{Kso} \mathrm{Pamb}=33.2 \mathrm{bar}$. The red vectors show examples of vectors rejected by the validation check. The nozzle tip is indicated by the blue cross.

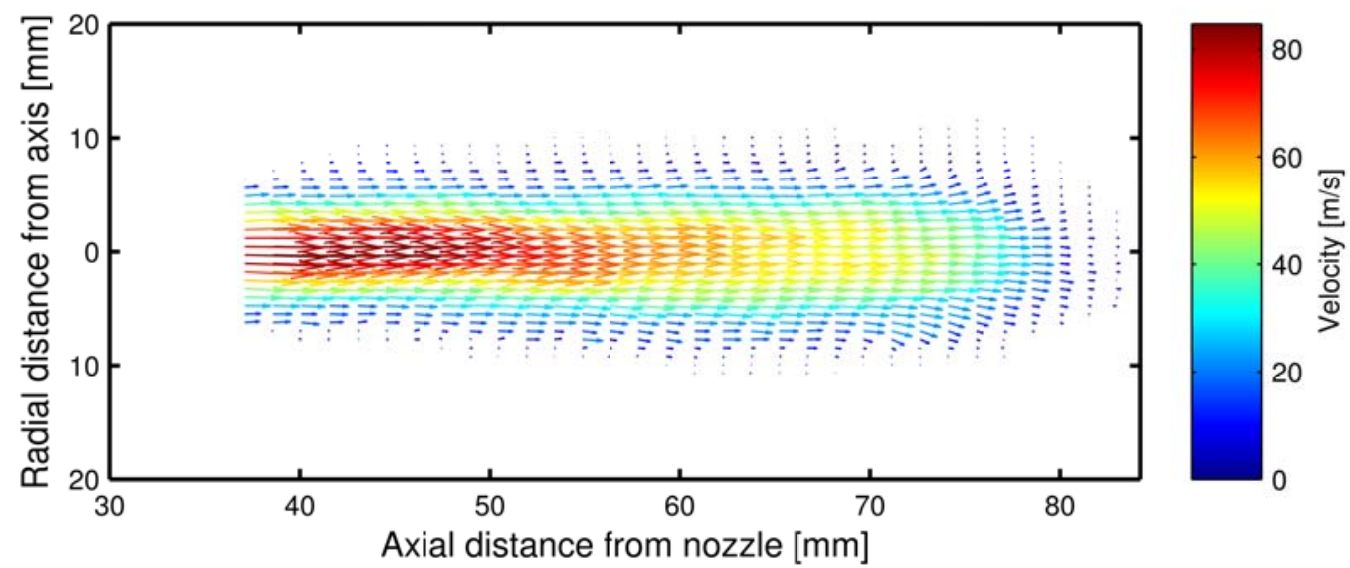

Fig. 3 Ensemble average velocity field obtained at $P$ inj $=1500 \mathrm{bar}, \rho_{a}=7.6 \mathrm{~kg} / \mathrm{m}^{3}, \mathrm{Tamb}=500 \mathrm{~K} \mathrm{so}$ Pamb $=11.0$ bar.

Published as: R. Payri et al. / International Journal of Multiphase Flow 80 (2016) 69-78 

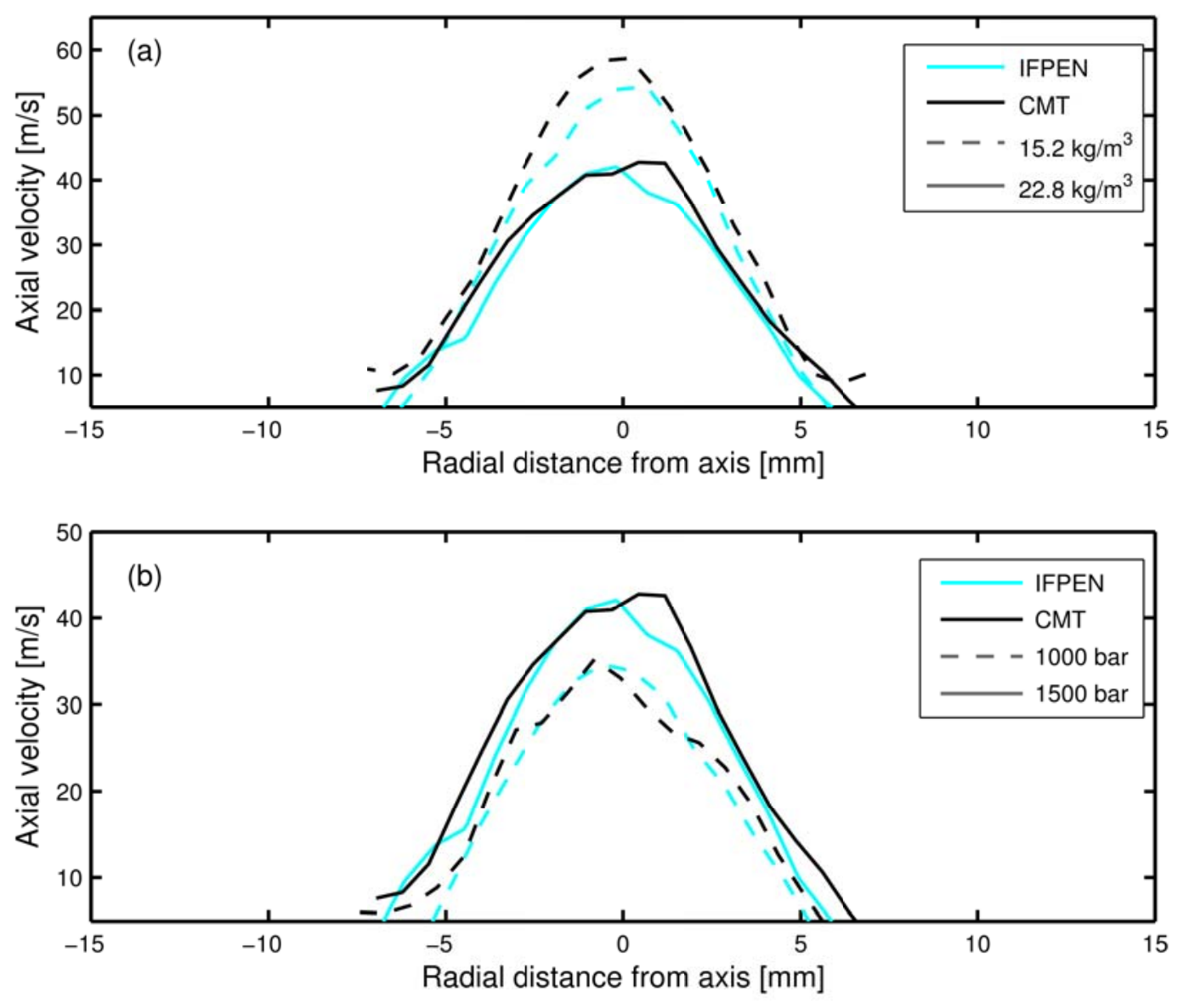

Fig. 4 Comparison between the ensemble average transverse cut profiles of axial velocity obtained at CMT and IFPEN PIV studies at (a) two different ambient densities and (b) two different injection pressures.

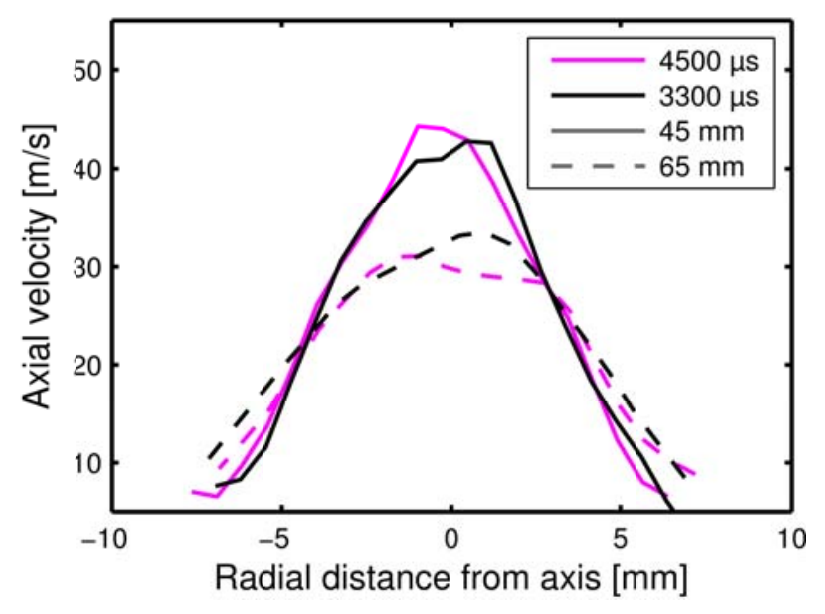

Published as: R. Payri et al. / International Journal of Multiphase Flow 80 (2016) 69-78 
Fig. 5 Ensemble average transverse cut profiles of axial velocity comparing different timing criteria at two axial locations. Times are measured from the injection trigger (SOE) and the axial locations are measured from the injector tip. Pinj $=1500 \mathrm{bar}, \mathrm{Pamb}=33.2 \mathrm{bar}, \mathrm{Tamb}=500 \mathrm{~K}$, so $\rho a=22.8 \mathrm{~kg} / \mathrm{m}^{3}$.

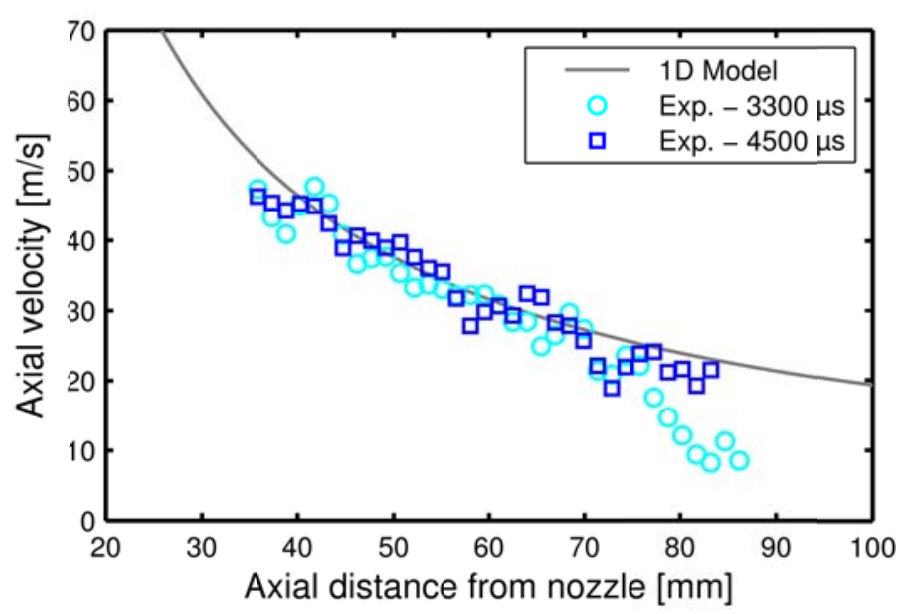

Fig. 6 Comparison between experimental (ensemble average) and predicted axial velocity profiles at Pinj $=1500$ bar, $P$ amb $=33.2 \mathrm{bar}, \mathrm{Tamb}=500 \mathrm{~K}$, so $\rho_{a}=22.8 \mathrm{~kg} / \mathrm{m}^{3}$. The two times shown represent, again, two separate experiments at different laser timings measured from the SOE.

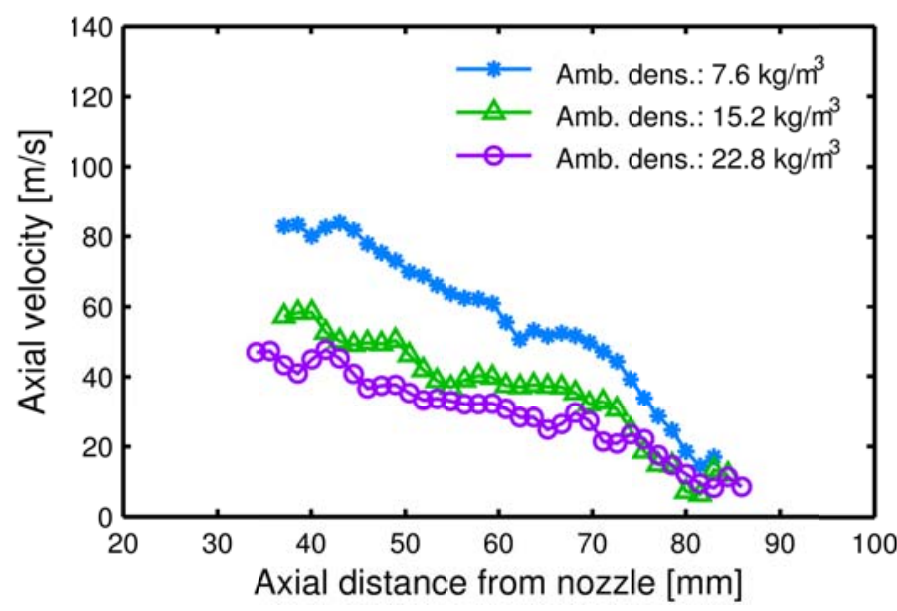

Fig. 7 Longitudinal ensemble average profiles of axial velocity illustrating the effect of the ambient density at Pinj $=1500$ bar, $\operatorname{Tamb}=500 \mathrm{~K}$. 


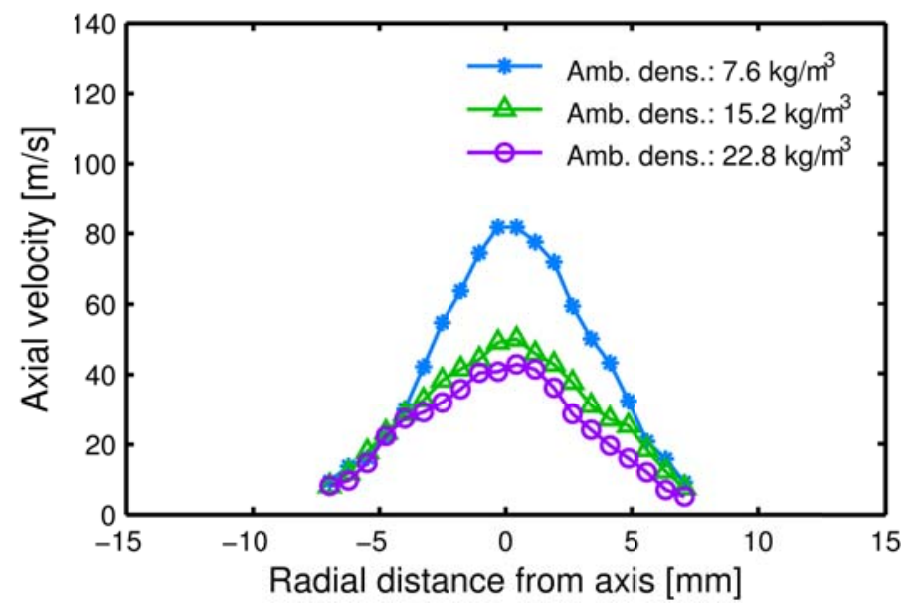

Fig. 8 Transverse cut ensemble average profiles of axial velocity illustrating the effect of the ambient density at $x=45 \mathrm{~mm}$, Pinj $=1500 \mathrm{bar}, \mathrm{Tamb}=500 \mathrm{~K}$.

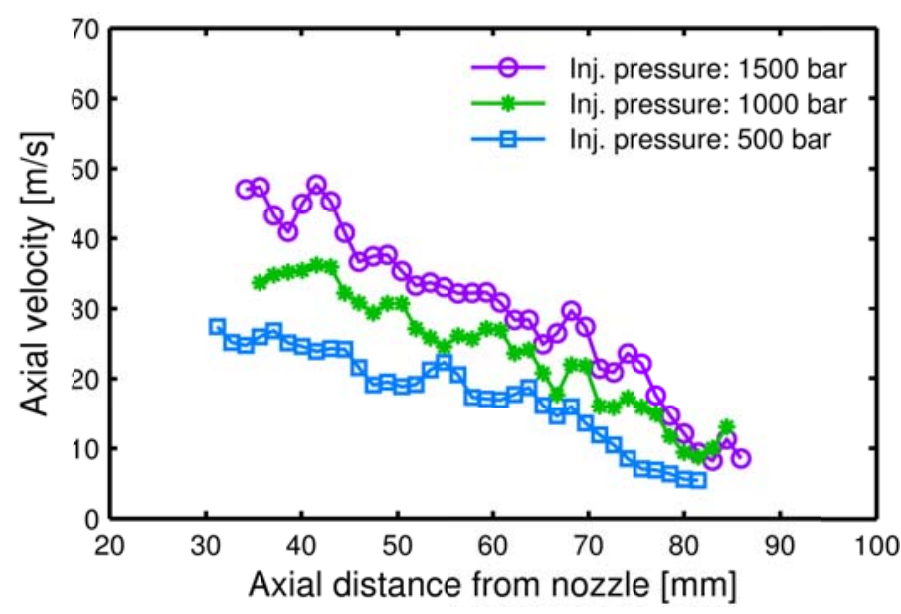

Fig. 9 Longitudinal ensemble average profiles of axial velocity illustrating the effect of the injection pressure at $\rho_{a}=22.8 \mathrm{~kg} / \mathrm{m}^{3}, \mathrm{Pamb}=33.2 \mathrm{bar}, \mathrm{Tamb}=500 \mathrm{~K}$.

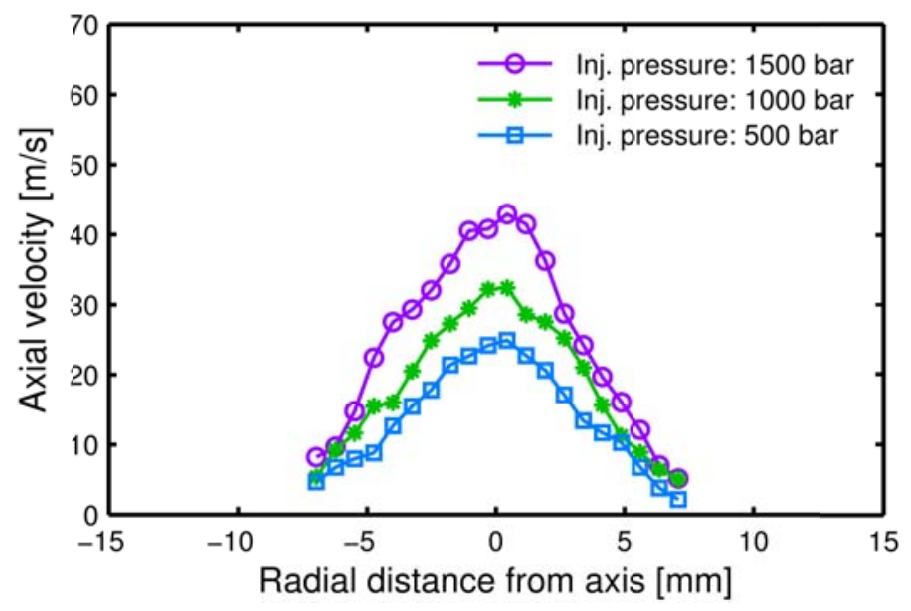

Fig. 10 Transverse cut ensemble average profiles of axial velocity illustrating the effect of the injection pressure at $x=45 \mathrm{~mm}, \rho_{a}=22.8 \mathrm{~kg} / \mathrm{m}^{3}, \mathrm{Pamb}=33.2 \mathrm{bar}, \mathrm{Tamb}=500 \mathrm{~K}$. 


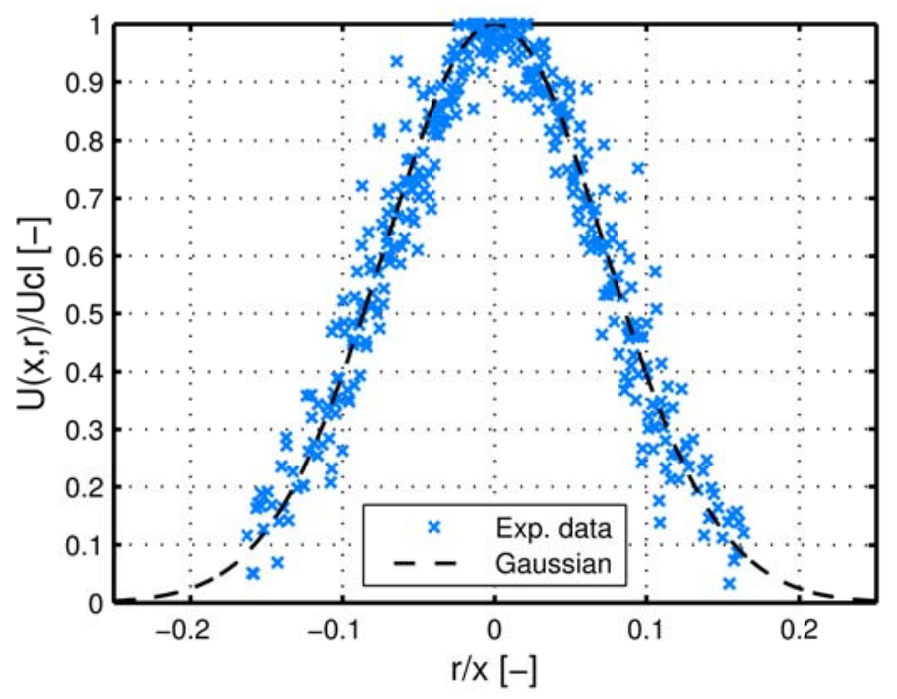

Fig. 11 Normalized transverse cut ensemble average profiles of axial velocity at $x=45 \mathrm{~mm}$ and $x=65$ $\mathbf{m m}$ for all injection pressures and ambient densities, compared to the theoretical Gaussian selfsimilar profile.
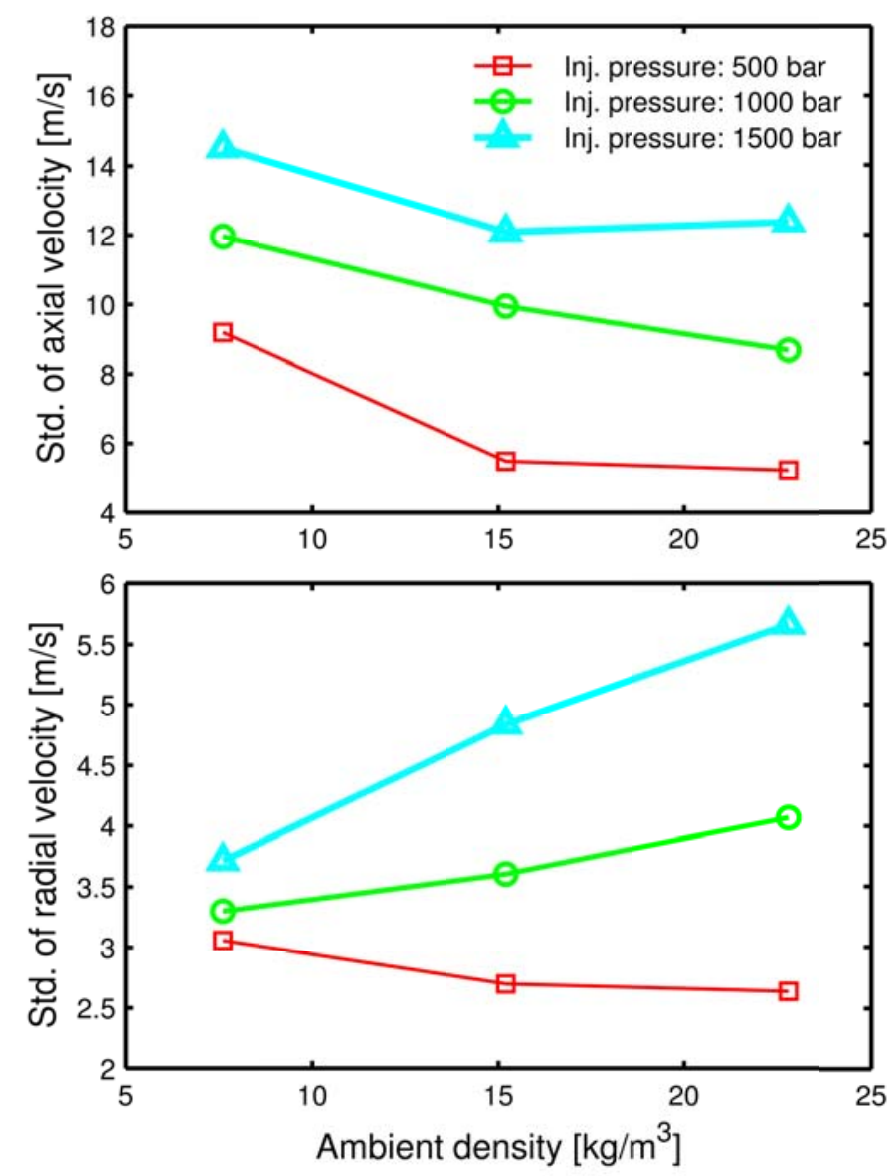

Fig. 12 Effect of the injection pressure and ambient density on axial and radial velocity fluctuations at $45 \mathrm{~mm}$ from the nozzle tip. 

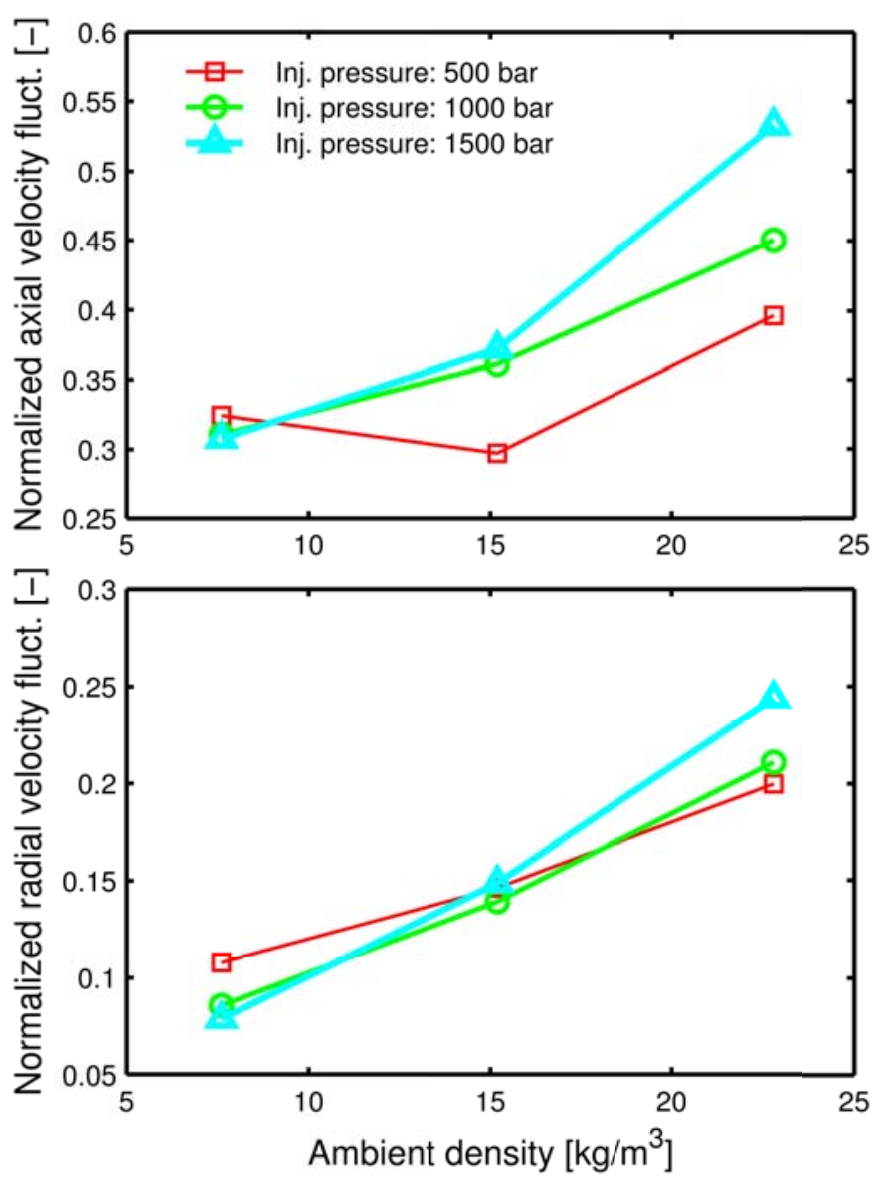

Fig. 13 Effect of the injection pressure and ambient density on the normalized axial and radial velocity fluctuations at $\mathbf{4 5} \mathbf{~ m m}$ from the nozzle tip. 